\title{
Upper Mississippi River Flow and Sediment Characteristics and Their Effect on a Harbor
} Siltation Case

Roberto Fernández, S.M. ASCE${ }^{1}$, Marcelo H. García, Dist. M. ASCE², and Gary Parker, M.ASCE ${ }^{3}$

${ }^{1}$ Ph.D. Student, Dept. of Civil and Environmental Engineering, Research Assistant, Ven Te Chow Hydrosystems Laboratory, Univ. of Illinois at Urbana-Champaign. 205 N Mathews Ave. Urbana, IL 61801. (Corresponding author). E-mail: fernan25@illinois.edu

${ }^{2}$ M.T. Geoffrey Yeh Chair, Dept. of Civil and Environmental Engineering, Director, Ven Te Chow Hydrosystems Laboratory, University of Illinois at Urbana-Champaign. 205 N. Mathews Ave. Urbana, IL 61801. E-mail: mhgarcia@illinois.edu

${ }^{3}$ Professor Dept. of Civil and Environmental Engineering, Ven Te Chow Hydrosystems Laboratory and W.H. Johnson Professor, Dept. of Geology, University of Illinois at Urbana-Champaign. 205 N. Mathews Ave. Urbana, IL 61801. E-mail: parkerg@illinois.edu

\section{Abstract}

Upper Mississippi River flow and sediment characteristics downstream of St. Louis, MO are presented in this study. Available and measured data were used to assess a harbor siltation case and dredging needs. Such data are also useful to researchers and engineers conducting work in the Mississippi River, and large rivers in general. Flows were characterized in terms of the mean annual hydrograph, the flow duration curve and the mean annual, dominant and effective discharges. Suspended and bed material sediments were characterized by grain size distributions (GSDs). Suspended sediment concentrations were characterized with a sediment-rating curve, a mean annual sediment-graph and a duration curve. The results of the analyses were used to assess harbor sedimentation by comparing GSDs of harbor bed samples with those observed in the river. Bathymetric surveys were used to determine rates and occurrence of sedimentation. The analyses showed that harbor siltation correlates with river conditions, and is driven by wash load in the river, which enters the harbor in suspension and deposits along the bottom due to the lack of flow-through velocities high enough to keep the fine sediments in suspension. 


\section{Key words}

Upper Mississippi River, Wash Load, Harbor, Siltation, Dominant discharge, Effective discharge

\section{Introduction}

Sediment characteristics and loads in the Mississippi River have been the subject of numerous studies in the past decades. Their relation with land loss (e.g. Kesel 1989, 1988; van Heerden and DeRouen 1997) has been one of the key factors driving the need to better assess the sediment loads in the river and its tributaries. Some recent studies on sediment load trends in the river basin (e.g. Horowitz 2010; Meade and Moody 2010; Blevins 2006) suggest that sediment loads are declining. In spite of this, potential for building river diversions that would carry sediment to certain locations along the shoreline to prevent further land loss at the Mississippi River delta, and along coastal Louisiana, has been recognized (e.g. Paola et al. 2011; Allison and Meselhe 2010). The amount of sediment diverted is a function of the flow and sediment load in the river (Dutta et al. 2017) and proper quantification of both variables is required. As a result, research has mainly focused on the Missouri and Ohio Rivers, which are responsible for the largest tributary sediment loads (Heimann et al. 2011), or on the lower Mississippi River sediment loads (e.g. Thorne et al. 2015). This study presents a characterization of the flow and sediment in the Upper Mississippi River at St. Louis, MO, to contribute to such efforts and facilitate future water and sediment diversions. In addition, the analysis and results are used to assess a siltation problem at a harbor built in 2006 on the right bank of the Upper Mississippi River close to Ste. Genevieve, MO.

Siltation is the process by which fine sediment particles suspended in a water body settle and deposit on the bed. Harbor siltation is a common problem throughout the world, and different sediment management strategies have been proposed in the literature to prevent it or slow it down and therefore reduce the necessity for dredging (e.g. Kirby 2011; Winterwerp 2005; van Schijndel 
and Kranenburg 1998; Berlamont 1989). Successful implementations of such strategies have been well documented (e.g. Kuijper et al. 2005; Winterwerp et al. 1994) but in spite of these, not all harbors, and especially not all riverine harbors, are designed with the potential consequences of siltation in mind.

Two distinct foci were established to assess the siltation problem which began a few months after the harbor started operating in 2007, namely, (i) the harbor itself and (ii) the Upper Mississippi River between St. Louis, MO and Chester, IL. Specific tasks involved the following:

- Harbor sediment sample collection and analysis. Samples were taken to the Ven Te Chow Hydrosystems Laboratory at the University of Illinois at Urbana-Champaign for their analysis.

- Determination of siltation volumes and average siltation rates from harbor bathymetric surveys provided by the harbor's owners.

- Characterization of the Upper Mississippi River flow conditions using data from neighboring United States Geological Survey (USGS) gaging stations. The data are available through the National Water Information System (USGS 2017).

- Characterization of the material in suspension and deposited on the bed in the Upper Mississippi River. These data are also available through the National Water Information System (USGS 2017).

These tasks set the structure of this paper. It is divided into five sections, with this introductory section being the first. The second section describes the harbor, its geometry and location, and presents measured siltation rates and patterns and bed sediment characteristics. The third section focuses on the characteristics of the flow and sediment in the reach of the Upper Mississippi River in the vicinity of the harbor. The fourth section presents the key findings from the tasks enumerated above, and provides answers regarding the following questions. (i) What is 
the source of the sediment responsible for siltation inside the harbor? (ii) When are these sediments most likely to be deposited? (iii) How does siltation relate to the hydraulic conditions in the river? The fifth and last section summarizes the conclusions of the analysis.

\section{Site Characteristics}

\section{Harbor Location and Dimensions}

The harbor is located between Upper Mississippi River Miles 138 and 139 as shown in Fig. 1. The site is approximately $65 \mathrm{~km}$ downstream of St. Louis, MO and $45 \mathrm{~km}$ upstream of Chester, IL. With a design maximum depth of $17 \mathrm{~m}$, the harbor is $500 \mathrm{~m}$ long and $200 \mathrm{~m}$ wide. The actual depth and volume of water in the harbor varies with river stage.

\section{Measured Harbor Siltation Rates and Patterns}

Siltation volumes inside the harbor are available for different dates due to bathymetric measurements conducted by the dredging company that was hired by the harbor's owners. Table 1 shows the siltation volumes measured between February of 2008 and June of 2010 . The number of days between surveys and the harbor's maximum surface area $\left(10,000 \mathrm{~m}^{2}\right)$ were used to compute mean siltation rates, equivalent deposit thicknesses and daily siltation depths. Siltation periods (dredging campaigns) are reflected by an increase (a decrease) in the excess volume of sediment reported in Table 1 . This volume corresponds to the difference between a given bathymetric survey and the harbor design geometry.

The patterns of sediment deposition inside the harbor are shown in Fig. 2 . The original harbor bathymetry is shown alongside bathymetric surveys conducted in January $26^{\text {th }}$, March $10^{\text {th }}$, June $04^{\text {th }}$ and July $28^{\text {th }}$ of 2009 . A small insert is included to indicate the relative position of the harbor with respect to the Mississippi River and the direction of flow. An aerial image of the harbor, taken from Google Earth, is also included. The amount of sediment deposited on the bed of the harbor 
in January $26^{\text {th }}, 2009$ corresponds to material that had accumulated previously and was not removed during the dredging efforts conducted in the second semester of 2008 (see Table 1).

\section{Harbor Bed Sediment Characteristics}

Grain Size Distributions

Samples from the harbor bed were extracted during two separate campaigns conducted in December of 2010 and December of 2011. Fig. 3 shows the sampling locations from both campaigns, and Table 2 indicates the size of the samples. Grain size distribution analyses for samples 1 and 5 were conducted according to the "Standard Test Method for Particle-Size Analysis of Soils" (ASTM 2002), referred to herein as the hydrometer method, and with the LISSTST settling tube (Pedocchi and Garcia 2006) for comparison. Results from both methods compared well (Fernández et al. 2012) and therefore samples 1-9 were analyzed only with the LISST-ST for simplicity. Samples from the 2011 campaign and from a drum collected in 2010 were analyzed with the hydrometer method. To assess the role of flocculation in the harbor, the analyses were conducted on samples dispersed with sodium hexametaphosphate $\left(\mathrm{NaPO}_{3}\right)_{6}$, as well as on non-dispersed samples. Results are shown in Fig. 4.

\section{Settling Velocities}

Results from the grain size distribution analyses on dispersed and non-dispersed samples suggest that flocculation occurs inside the harbor. Flocculation may lead to enhanced siltation rates through faster settling of material. The settling velocity of the flocs depends on the size, density and shape, which in turn are governed by inter-particle collision frequency (Mehta and McAnally 2008). Krone (1962) suggested that since particle collision frequency depends on the concentration of particles in suspension, suspended particle concentration may be used as a surrogate to estimate the floc settling velocity. Wolanski et al. (1989) proposed dividing the settling process into four zones; empirical relations have been developed to express settling velocity in each zone as a function of suspension concentration. Table 3 shows the different zones; an 
empirical relation proposed by Hwang (1989) to estimate settling velocities in each zone is given by Eq. 1 .

$$
w_{s}=\left\{\begin{array}{cl}
w_{s f} & C<C_{1} \\
a_{w} \frac{C^{n_{w}}}{\left(C^{2}+b_{w}^{2}\right)^{m_{w}}} & C_{1}<C<C_{2} \\
\sim \text { negligible } & C_{3}<C<C_{3}
\end{array}\right.
$$

131 where

$w_{s f} \quad=$ free settling velocity;

$C \quad=$ volume suspension concentration;

$134 a_{w} \quad=$ velocity scaling coefficient;

$135 n_{w} \quad=$ flocculation settling exponent;

$136 b_{w} \quad=$ hindered settling coefficient;

$137 m_{w} \quad=$ hindered settling exponent;

$138 C_{1}-C_{3}=$ zone concentration limits as defined in Table 3;

When the suspension concentration is below a value $C_{1}$, free settling occurs and the settling velocity corresponds with the one each particle would have in the absence of other particles. Particles are far away from each other and no flocculation occurs. As concentrations increase, flocculation begins to occur and therefore the original grains begin to form flocs which have higher settling velocities. This process of flocculation settling continues up to a concentration $\mathrm{C}_{2}$, which corresponds with the maximum settling velocity $\left(\mathrm{w}_{\mathrm{sm}}\right)$. Above $\mathrm{C}_{2}$, the concentration becomes so high that the flocs have trouble settling and begin to collide with each other. Settling becomes hindered and could be thought of as a condition where water is trying to escape the pore space as sediment settles down. If concentration continues to increase and reaches a value $C_{3}$, the process turns into a consolidation process rather than a settling one. Zone concentration limits and coefficients are not universal and depend on the sediment type and grain size distribution, as 
well as the environmental conditions in which the settling process takes place, such as salinity and turbulence or the lack thereof.

The settling velocity of the material found in the harbor was determined by conducting the settling column experiments first described by McLaughlin (1959) and later improved by Ross (1988). Fig. 5 shows the settling column used. It is $0.10 \mathrm{~m}$ in diameter and $1.9 \mathrm{~m}$ high, and has $5 \mathrm{~mm}$ sampling tubes located at the following elevations above the bed: $0.06 \mathrm{~m}, 0.16 \mathrm{~m}, 0.31 \mathrm{~m}, 0.51 \mathrm{~m}, 0.72 \mathrm{~m}$, $0.93 \mathrm{~m}, 1.13 \mathrm{~m}, 1.33 \mathrm{~m}$ and $1.54 \mathrm{~m}$. The design of the column is based on the one developed by Lott (1987), and the experimental procedure followed the one described by Ross (1988). The following five different initial concentration conditions: $C_{0}=1 \mathrm{~g} / \mathrm{L}, 5 \mathrm{~g} / \mathrm{L}, 10 \mathrm{~g} / \mathrm{L}, 15 \mathrm{~g} / \mathrm{L}$, and $25 \mathrm{~g} / \mathrm{L}$ were used. Results from the experiments are shown in Fig. 6 along with a curve fit with Eq.1; the resulting coefficients are shown in Table 4.

\section{Upper Mississippi River Characteristics in the Near-Harbor Area}

\section{Available Data}

Data available at USGS gaging stations 07010000 at St. Louis, MO and 07020500 at Chester, IL were used to characterize the Mississippi River in the vicinity of the harbor. A summary of the data is shown in Table 5. Given that no significant tributaries flow into the Mississippi River between St. Louis, MO and Chester, IL a preliminary analysis showed that for the matching period of record July 1942 - November 2011 the flow conditions, on average, differ by less than $1 \%$ (Fernández et al. 2012). Therefore, all analyses related to river data presented hereafter only used the information recorded at St. Louis, MO.

\section{Flow Discharge and Suspended Sediment Concentrations}

Flow discharge and sediment concentrations in the Mississippi River at St. Louis, MO for the period October $1^{\text {st }}, 1980$ to September $30^{\text {th }}, 2011$ are shown in Fig. 7. Historic mean flows at St. Louis, MO computed for different periods are shown in Table 6. Values reported therein indicate 
that the mean flow in the Mississippi River for the period beginning when the harbor started operation (2007) and ending in 2011 has been approximately $56 \%$ larger than what it had been over the period beginning in 1861 and ending in 2011 and 33\% larger than what it had been over the period beginning in 1980 and ending in 2011.

A suspended sediment concentration rating curve determined from the 11,285 measurements available for the 30 year period is shown in Fig. 8. A power law curve shown in Eq. 2 and on the lower right of Fig. 8, was fit to the data (solid line) and envelopes indicating concentration values equal to $0.2,0.5,2.0$ and 5.0 times the values estimated with the power curve fit to the data are indicated with dashed lines. Although the data shows scatter, $80.4 \%(99.3 \%)$ of the data lie inside the envelopes for $0.5-2.0(0.2-5.0)$ times the value obtained with the power law relation.

$$
C=1.022 e^{-05} Q^{1.1641}
$$

where

$C=$ suspended sediment concentration $[\mathrm{g} / \mathrm{L}] ;$ and

$Q=$ flow discharge $\left[\mathrm{m}^{3} / \mathrm{s}\right]$.

\section{Suspended and Bed Material Sediment Characteristics}

Grain size distributions for the sediments in the Mississippi River at St. Louis, MO were available as part of U S Geological Survey field/lab water quality samples (Table 5). Fig. 9 shows a total of 108 grain size distributions of the material traveling as suspended load and Fig. 10 shows a total of 114 grain size distributions for the material found on the bed of the Mississippi River at St. Louis, MO. The solid black line represents the median grain size distribution curve, and the dashed lines correspond to the $75^{\text {th }}$ and $25^{\text {th }}$ percentiles. The sediment size for which $50 \%$ of the grains are smaller is $0.008 \mathrm{~mm}$ for the material traveling as suspended load and $0.44 \mathrm{~mm}$ for the material found on the bed of the river. 
203 The mean annual flow hydrograph and mean annual sediment concentrations are shown in Fig. 11. A black dashed line spike can be seen in the sediment concentration hydrograph during late February. That line corresponds to the 30 -year daily average concentrations but it is significantly biased by an extreme event that occurred in February of 1985, as shown in Table 7. If the values for those days are not included in the averaging process, the curve takes the shape of the solid line, which was taken as the representative mean annual sediment concentration curve herein. Fig. 12 shows the flow duration curve and the suspended sediment concentration duration curve based on the mean annual data in Fig. 11. Flows (concentrations) are lower than $5,000 \mathrm{~m}^{3} / \mathrm{s}(0.27$ $\mathrm{g} / \mathrm{L})$ for half of the year and higher than $8,000 \mathrm{~m}^{3} / \mathrm{s}(0.43 \mathrm{~g} / \mathrm{L})$ for $30 \%$ of the year. The remaining $20 \%$ of the time covers the periods in which flows and suspended sediment concentrations increase (decrease) rapidly between mid-February and mid-March (mid-July and mid-August).

\section{Characteristic Flow Discharges}

Different definitions of a constant characteristic discharge that would be capable of producing the same channel morphologies observed in a river under varying flow conditions have been proposed in the literature. Some of these definitions are related to channel equilibrium conditions (e.g. Inglis 1947), meander wavelengths (e.g. Ackers and Charlton 1970), stream bankfull geometry (e.g. Wilkerson and Parker 2011; Nixon 1959), exceedance probability (e.g. Blench 1956; Leopold and Maddock 1953) or sediment transport capabilities (e.g. Terrell and Borland 1958). These concepts are typically applied in relation to geomorphic processes and their effect on channel geometry.

In this study, the concept of characteristic discharges is adapted to assess the flows responsible for the sediment loads in the Upper Mississippi River. Specifically, the concepts of dominant and effective discharge are used due to their relation with sediment loads in the river without consideration for morphological implications. The dominant discharge is defined here as the flow 
that, if sustained throughout a period of time, would produce the same mean sediment discharge observed during that period under varying flow conditions. The effective discharge is defined here as the one carrying the largest volume of sediment in the river. This definition is based on the bed-generative discharge concept first proposed by Schaffernak $(1916,1922)$, and its computation follows the approach described by Biedenharn et al. (2000). The method has been used and described by different authors (e.g. Garde and Ranga Raju 1977; Gandolfo 1940) but other authors refer to it as the dominant discharge (e.g. Thomas and Benson 1966). It is not the objective of this study to provide clarification and comparison between available definitions; the reader is referred to Soar and Thorne (2011) for a recent review on the subject.

Using the data available for the 1981-2011 period, the mean annual suspended sediment concentration was determined and the dominant discharge was back calculated with the sediment-rating curve shown in Fig. 8 and Eq. 2 . The values obtained are $0.337 \mathrm{~g} / \mathrm{L}$ for the mean concentration and $7,608 \mathrm{~m}^{3} / \mathrm{s}$ for the dominant discharge.

The effective discharge computation is shown in Fig. 13. The resulting value is $9,582 \mathrm{~m}^{3} / \mathrm{s}$, which corresponds to the maximum value of the curve of weighted contributions (right panel) obtained from the product of the flow frequency curve (left panel) and the sediment rating curve (middle panel). Other local maxima may be seen in the curve. These represent the discharges responsible for carrying large sediment volumes. As is often the case, the result obtained has two distinctive peaks, indicating that a frequent discharge carrying a relatively small sediment load for a long time is almost as effective as an infrequent discharge carrying a large amount of sediment over a shorter period of time. Using the rating curve in Fig. 8, the suspended sediment concentration associated with the effective discharge was obtained. The resulting value was $0.441 \mathrm{~g} / \mathrm{L}$. 


\section{Key Findings and Discussion}

\section{What is the source of the sediment responsible for siltation inside the harbor?}

\section{Origin based on grain size distributions and sedimentation patterns}

The sediment size analyses from the river and the harbor are summarized in Fig. 14 ; median $D_{50}$ values are shown in Table 8 . Harbor bed sediments are slightly coarser than the material that is carried in suspension by the Upper Mississippi River at St. Louis, MO but are significantly finer than the material in the bed of the river, suggesting that the sediment source is likely to be the suspended sediment in the river. The sedimentation patterns inside the harbor also shed light on the origin of the sediment. As shown in Fig. 2, siltation blankets the entire bed of the harbor. The relatively uniform thickness of the deposited sediment observed in the March and June bathymetries is due to a combination of two factors: the fine-grained nature of the deposited sediment, and barge traffic (approximately 20 barges per day), which can under some conditions cause resuspension and redistribution due to propeller wash (Garcia et al. 1999). Although coarser materials were found close to the entrance, all sediments were significantly finer than the Upper Mississippi River bed material.

\section{Suspended sediment dynamics within the harbor}

The sediment that enters the harbor in suspension is deposited first on the perimeter of the harbor where the flow velocities and shear stresses, even in the presence of barge traffic, approach zero. Sediment deposits preferentially along these zones and then builds up uniformly from the edges towards the middle of the harbor. The siltation patterns shown in Fig. 2 show some zones that are lower in elevation in the south section close to the entrance. These areas have likely been scoured due to barge traffic going in and out of the harbor.

The settling velocities determined in the experiments (Fig. 5) and shown in Fig. 6 range between 1e-6 to $1 \mathrm{e}-3 \mathrm{~m} / \mathrm{s}$, with the largest values associated with larger suspended sediment concentrations at which flocculation occurs. Although the concentrations in the Mississippi River rarely exceed $2 \mathrm{~g} / \mathrm{L}$ (Fig. 8), it is possible that concentrations may exceed this value inside the 
harbor as the sediment settles to the bottom. This is most likely to prevail during periods when the harbor is not operating at full capacity. The presence of a bar-like feature on the east side of the harbor on the July $29^{\text {th }}$ bathymetry is also thought to be related to barge traffic redistribution of sediments, since most of the barge traffic occurs through the southern part of the harbor and towards the west and north west sections.

\section{When are the sediments most likely to be deposited in the harbor?}

Harbor siltation volumes and rates are shown in Fig. 15. The black solid line corresponds with the volumes of sediment above the design conditions of the harbor. The values are divided by 20 so as to plot this variable using the same axis limits as the flow discharge, and to clearly present the salient trends. In the three cases where the volume of sediment in the harbor increases, the period corresponds to late February or early March to late July or early August. (Decreases are caused almost solely by dredging.) This timeframe corresponds to the spring and early summer months; siltation rates within this period can be as high as $1.2 \mathrm{~cm} / \mathrm{m}^{2} /$ day, as indicated by the red dashed line.

\section{Applicability of the dominant and effective discharge concepts}

Typically, the dominant and effective discharge concepts are not meant to be used in rivers where the majority of the material transported corresponds to silt and clay sizes (i.e. wash load). The main reason for this is that wash load does not correlate with flow discharge and therefore, as long as the sediment is available, the river will transport it regardless of the flow magnitude. Fig. 14 shows that more than $80 \%$ of the material traveling in suspension in the Upper Mississippi River corresponds to wash load. However, Fig. 8 and Fig. 11 show that wash load in the Mississippi River, as defined using e.g. the $62.5 \mu \mathrm{m}$ cutoff criterion (River Research Council, 2007), does indeed positively correlate with discharge to a surprising degree. The trends shown by both variables in Fig. 11 are remarkably similar, and more than $80 \%$ of the suspended sediment concentration data shown in Fig. 8 lies within envelopes of 0.5-2.0 times the value estimated with the sediment rating curve. A possible explanation for this behavior is given below. 
During late February and early March, snowmelt takes place and river flows increase. At the same time, fine sediment from bare agricultural land is carried by runoff into the river and transported as wash load. This phenomenon is sustained throughout the growing season, and is enhanced by rainfall in the spring and early summer. Once the crops are established and precipitation diminishes (late summer), fine sediment availability is reduced and both the flows and suspended sediment concentrations in the river return to their base flow patterns. The mean annual hydrograph shown in Fig. 11 reflects these processes.

Snowmelt followed by spring and early summer precipitation contribute to the flow magnitude and the availability of sediment due to bare agricultural land in the Upper Mississippi River basin, thus creating conditions in which fine sediment availability matches the period of high flows. High flows do not necessarily cause larger sediment transport, but are correlated due to the characteristics of the river basin. The dominant and effective discharge concepts may be applied in this and other river basins where sediment availability matches the period of high flows even though the relation between the two variables is not strictly causal.

\section{How does siltation relate to the hydraulic conditions in the river?}

Table 9 summarizes the results obtained for the characteristic discharges, the number of days for which they are exceeded and the associated suspended sediment concentrations. Comparison of the characteristic discharges with the mean annual hydrograph and mean annual suspended sediment concentrations shown in Fig. 11 suggest that the Mississippi River carries larger sediment volumes between the end of February and early August than otherwise.

The dominant discharge is exceeded for 120 days between mid-March and mid-July, and the effective discharge is exceeded only for a few days in April and all of May. Siltation volumes and siltation rates are shown in Table 1 and Fig. 15; they are greatest in periods including these months. Although bathymetric survey dates allow assessment of the silting process over the period between February and August, lack of data for the months of April and May impede determining if harbor siltation occurs mostly during early or late spring, summer or both. 
Nonetheless, the process of siltation is clearly related to flow conditions in the river. The data show that whenever suspended sediment concentrations at St. Louis, MO are above $0.44 \mathrm{~g} / \mathrm{L}$, large siltation volumes inside the harbor are possible. According to Fig. 12, these concentrations are met during $30 \%$ of the year.

\section{Potential Effect of Barge Traffic and Towboat Operations on Harbor Siltation}

Studies on the effect of towboat navigation and barge tows under typical conditions of Upper Mississippi River traffic have shown that bed shear stresses under such conditions deviate from those expected under steady-uniform flow. More specifically, higher shear stresses are associated with the passage of the tow and the stern of the barge tow (Rodriguez et al. 2002; Garcia et al. 1999, 1998). Barge traffic in and out of the harbor plays an important role in sediment resuspension. The harbor is directly open to the Mississippi River, but has no through-flow discharge and thus acts as a sediment trap. Towboats and barges that enter for loading and unloading operations resuspend the sediment in the harbor, but even with the small settling velocities measured in the laboratory and reported in Fig. 6, such resuspension does not seem to contribute substantially toward keeping sediment from settling inside the harbor. As shown in Table 1 and Fig. 15, between the months of July and December of 2009, the excess volume of sediment in the harbor decreased and no dredging efforts took place. This suggests that in those months in which Upper Mississippi River flow discharge and suspended sediment concentrations return to base levels, sediment resuspended by towboats and barges may leave the harbor. This observed decrease, however, corresponds to only an insignificant amount of sediment compared to the amount that comes into the harbor during the spring and summer months.

\section{Conclusions}


Flow and sediments in the Upper Mississippi River were characterized with information available at the USGS gaging station in St. Louis, MO. The most relevant results of our analysis are as follows.

1. The correlation between wash load and flow discharge in the Upper Mississippi River is due to the characteristics of the basin, namely, snowmelt followed by spring and early summer precipitation over bare agricultural land that create conditions in which fine sediment availability matches the period of high flows.

2. The dominant and effective discharge concepts may be applied to the Upper Mississippi River and similar basins where these conditions are met.

3. The $D_{50}$ for the material carried in suspension by the Mississippi River at St. Louis, MO is $0.008 \mathrm{~mm}$ and for the material found on the bed it is $0.44 \mathrm{~mm}$.

4. Settling velocities for the material carried in suspension by the Mississippi River in St. Louis, MO are between $1 \mathrm{e}-6$ to $5 \mathrm{e}-4 \mathrm{~m} / \mathrm{s}$ with the largest values associated with larger suspended sediment concentrations where flocculation is possible.

Comparison of the Upper Mississippi River data with laboratory results of harbor bed samples and bathymetric survey data leads to the following findings:

5. Sediment deposited in the harbor is wash load from the Upper Mississippi River that enters the harbor in suspension and deposits due to the lack of flow-through inside;

6. Towboat and barge operations resuspend sediment, but their effect on preventing siltation is negligible in spite of the small settling velocities;

7. Flow conditions in the Upper Mississippi River in the period between Mid-March and MidJuly correlate with high siltation rates inside the harbor; the analysis suggest (but in the absence of specific bathymetric data does not prove) that large siltation rates are possible in the month of May when the effective discharge in the Mississippi River is exceeded. 


\section{Acknowledgements}

The authors would like to thank Fernando Valencia, GV Terminal Manager at the time this study was conducted. Participation of all authors in this study was possible thanks to financial support provided by Holcim US through its St. Genevieve Plant in Missouri. The authors would also like to thank the anonymous reviewers and the associate editor for their valuable feedback.

\section{References}

Ackers, P., and Charlton, F.G. (1970). Dimensional Analysis of Alluvial Channels with Special Reference to Meander Length. Journal of Hydraulic Research, Vol. 8, No. 3. pp. 287-316.

Allison, M. A., and Meselhe, E.A. (2010). The use of large water and sediment diversions in the lower Mississippi River (Louisiana) for coastal restoration. Journal of Hydrology 387(3), pp. 346360.

American Society for Testing and Materials ASTM (2002). Standard Test Method for ParticleSize Analysis of Soils. ASTM International, PA, United States, pp. 1-8

Biedenharn, D. S., Copeland, R. R., Thorne, C. R., Soar, P., Hey, R.D., and Watson, C.C. (2000). Effective Discharge Calculation: A Practical Guide US Army Corps of Engineers, ERDC/CHL; TR-00-15, 63 pages.

Berlamont, J. (1989). Pumping fluid mud: theoretical and experimental considerations. Journal of Coastal Research, Special Issue No. 5. High Concentration Cohesive Sediment Transport. pp. 195-205, Fort Lauderdale, FI.

Blench, T. (1956). Regime Bahaviour of Canals and rivers. Butterworths Scientific Publication, London, 87 pages.

Blevins, D. W. (2006) The response of suspended sediment, turbidity, and velocity to historical alterations of the Missouri River: U.S. Geological Survey Circular 1301, 8 p. 
401

402

403

404

405

406

407

408

409

410

411

412

413

414

415

416

417

418

419

420

421

422

423

Dutta, S., Wand, C., Tassi, P. and Garcia, M.H. (2017) Three-Dimensional Numerical Modeling of the Bulle-Effect: the non-linear distribution of near-bed sediment at fluvial diversions. Earth Surface Processes and Landforms. DOI: 10.1002/esp.4186

Fernández, R., Santacruz, S., Tokyay, T., Waratuke, A., Garcia, M.H., and Parker, G. (2012). Holcim Ste. Genevieve Missouri - Harbor Siltation Study. Civil Engineering Studies. Hydraulic Engineering Series No. 102. UIUC-ENG-2015-2006. ISSN 0442-1744. 71 pages. Champaign, IL, United States.

Gandolfo, J. (1940). Estudio de la evolución fluvial que determina el endicamiento del río San Juan. (in Spanish). Universidad Nacional de la Plata, Publicaciones de la Facultad de Ciencias Fisicomatemáticas, La Plata, Argentina.

Garcia, M.H., Admiraal, D.M., and Rodriguez, J. (1999) Laboratory Experiments on NavigationInduced Bed Shear Stresses and Sediment Resuspension. Journal of Sediment Research, 14(2), pp. 303-317.

Garcia, M.H., Admiraal, D.M., Rodriguez, J., and Lopez, F. (1998) Navigation-Induced Bed Shear Stresses: Laboratory Measurements, Data Analysis, and Field Application. Civil Engineering Studies. Hydraulic Engineering Series No. 056. UIUC-ENG-98-2002. ISSN 04421744. 139 pages. Champaign, IL, United States.

Garde, R. J., and Ranga Raju, K.G. (2006) Mechanics of Sediment Transportation and Alluvial Stream Problems. New Age International Limited. Third Ed. Reprint 2006. New Delhi, India, pp. 340-343.

Heimann, D.C., Sprague, L.A., and Blevins, D.W. (2011) Trends in suspended-sediment loads and concentrations in the Mississippi River Basin, 1950-2009: U.S. Geological Survey Scientific Investigations Report 2011-5200, 33 p. 
Horowitz, A.J. (2010) A quarter century of declining suspended sediment fluxes in the Mississippi River and the effect of the 1993 flood: Hydrological Processes, v. 24, p.13-34.

Hwang, K.-N. (1989) Erodibility of fine sediment in wave dominated environments. MS Thesis, University of Florida, Gainsville, Florida. 159 pages.

Inglis, C.C. (1947) Meanders and Their Bearing on River Training. Proceedings of the Institution of Civil Engineers, Maritime Paper No. 7, London.

Kesel, R.H. (1988) The decline in the suspended sediment load of the lower Mississippi River and its influence on adjacent wetlands: Environmental Geology and Water Sciences, v. 11, p. $271-281$.

Kesel, R.H. (1989) The role of the Mississippi River in wetland loss in southeastern Louisiana, USA: Environmental Geology and Water Sciences, v. 13, p. 183-193.

Kirby, R. (2011) Minimising harbour siltation - findings of PIANC Working Group 43. Ocean Dynamics, 61(2-3), pp. 233-244.

Krone, R.B. (1962) Flume studies of the transport of sediment in estuarial shoaling processes. Final Report, hydraulic engineering Laboratory and Sanitary Engineering Research Laboratory, University of California, Berkeley, California. 110 pages.

Kuijper, C., Christiansen, H., Cornelisse, J. M., and Winterwerp, J.C. (2005). Reducing Harbor Siltation. II: Case Study of Parkhafen in Hamburg. Journal of Hydraulic Engineering 131(6) pp. 267-276. DOI: 10.1061/(ASCE)0733-950X(2005)131:6(267)

Leopold, L.B., and Maddock, T. (1953) The Hydraulic Geometry of Stream channels and Some Physiographic Implications. USGS Professional Paper 252, Washington D.C., 64 pages.

Lott, J. W. (1987). Laboratory Study on the Behavior of Turbidity Current in a Closed-end Channel. M.S. Thesis. University of Florida Gainesville, Florida. 
McLaughlin, R.T. Jr. (1959). The Settling Properties of Suspensions. Journal of the Hydraulics Division, American Society of Civil Engineers. Vol. 85, No. HY 12, pp. 9-41.

Meade, R.H., and Moody, J.A. (2010) Causes for the decline of suspended-sediment discharge in the Mississippi River system, 1940-2007: Hydrological Processes, v. 24, p. 35-49.

Mehta, A. J., and McAnally, W.H. (2008) Fine-Grained Sediment Transport in Sedimentation Engineering Processes, Measurements, Modeling and Practice (Garcia, M.H. ed.) American Society of Civil Engineers. ASCE Manuals and Reports on Engineering Practice No. 110, pp. 253-306.

Nixon, M.A. (1959) Study of the Bankful Discharges of Rivers in England and Wales, Proceedings of the Institution of Civil Engineers, London, pp. 157-174.

Paola, C., Twilley, R.R., Edmonds, D.A., Kim, W., Mohrig, D., Parker, G., Viparelli, E. and Voller, V. R. (2011) Natural Processes in Delta Restoration: Application to the Mississippi Delta. Annual Review of Marine Science, Vol. 3 p. 67-91.

Pedocchi, F., and and Garcia, M.H. (2006) Evaluation of the LISST-ST instrument for suspended particle size distribution and settling velocity measurements. Continental Shelf Research, Vol 26, pp. 943-958. doi: 10.1016/j.csr.2006.03.006

River Research Council, Division on Earth and Life Studies, Water Science and Technology Board, Committee on River Science at the U.S. Geological Survey. (2007) River Science at the U.S. Geological Survey. National Academic Press, p.87.

Rodriguez, J., Admiraal, D.M., Lopez, F., and Garcia, M.H. (2002) Unsteady Bed Shear Stresses Induced by Navigation: Laboratory Observations. Journal of Hydraulic Engineering, 10.1061/(ASCE)0733-9429(2002) 128(5), pp. 515-526.

Ross, M.A. (1988) Vertical Structure of Estuarine Fine Sediment Suspensions. PhD Thesis, University of Florida, United States, 112 pages. 
Schaffernak (1916) Die Theorie des Geschiebebetriebes und ihre Anwendung. Zeitschrift des oesterrichischen Ingenieur - und Architekten - Vereines. Wien. Nr. 68.

Schaffernak (1922) Neue Grundlagen für die Berechnung der Geschiebeführung in Flussläufen. Verlag: Franz Deutike. Leipzig-Wien.

Soar, P.J., and Thorne, C.R. (2011) Design Discharge for River Restoration in Stream Restoration in Dynamic Fluvial Systems (eds. Simon, A., Bennett, S.J. and Castro, J.M.), American Geophysical Union, Washington D.C. doi: 10.1029/2010GM001009.

Terrell, P. W., and Borland, W. M., (1958) Design of Stable Canals and Channels in Erodible Material. Transactions of the American society of Civil Engineers, 123(1), pp. 101-115.

Thomas, D. M., Benson, M.A. (1966) A definition of dominant discharge. International Association of Scientific Hydrology. Bulletin 11:2, 76-80.

Thorne, C., Knuuti, K., Harmar, O., Watson, C., Clifford, N., and Biedenharn, D. (2015) Recent and Historical Sediment Loads in the Lower Mississippi River. Proceedings of the $3^{\text {rd }}$ Joint Federal Interagency Conference on Sedimentation and Hydrologic Modeling. Reno, Nevada, USA.

US Army Corps of Engineers (2011) Upper Mississippi River Navigation Charts, Chart No. 135 River Mile 136 - 142. Retrieved from http://www.mvr.usace.army.mil/Portals/48/docs/Nav/NavigationCharts/UMR/CHART 135.pdf U.S. Geological Survey, 2017, National Water Information System data available on the World Wide Web (USGS Water Data for the Nation), accessed August 21, 2017 at URL http://waterdata.usgs.gov/nwis/.

van Heerden, I., and K. DeRouen, K., Jr. (1997) Implementing a barrier island and barrier shoreline restoration program — the state of Louisiana's perspective: Journal of Coastal Research, v. 13, p. 679-685. 
495 van Schijndel S.A.H., and Kranenburg C. (1998) Reducing the siltation of a river harbour, 496 Journal of Hydraulic Research, 36:5, 803-814, DOI: 10.1080/00221689809498604

497 Wilkerson, G. V., and Parker, G. (2011) Physical Basis for Quasi-Universal Relationships 498 Describing Bankfull Hydraulic Geometry of Sand-Bed Rivers. Journal of Hydraulic Engineering, 499 137(7), pp. 738-753. DOI: 10.1061/(ASCE)HY.1943-7900.0000352.

500 Winterwerp, J.C. (2005) Reducing Harbor Siltation. I: Methodology. Journal of Waterway, Port, 501 Coastal, and Ocean Engineering 131(6) pp. 258-266. 10.1061/(ASCE)0733-

$502950 \times(2005) 131: 6(258)$

503 Winterwerp, J.C., Eysink, W.D., Kruiningen, F.W., Christiansen, H., Kirby, R. and Smith, T.J.

504 (1994). The current deflecting wall: A device to minimize harbor siltation. Dock Harbor Authority. 505 74(849), pp. 243-247.

506 Wolanski, E., Asaeda, T., and Imberger, J. (1989) Mixing across a lutocline. Limnology and 507 Oceanography, 34(5), pp. 931-938. 
Fig 1. Harbor Location. Figure prepared by the authors based on Navigation Chart No. 135 for the Upper Mississippi River (US Army Corps of Engineers 2011).

Fig. 2. Sedimentation patterns inside the harbor based on original harbor bathymetry and bathymetric surveys at four different dates in 2009.

Fig. 3. Sediment sampling locations. Samples 1-8 and the drum were extracted in December of 2010. Samples A, B and C were extracted in December of 2011.

Fig. 4. Grain size distributions of harbor bed samples.

Fig. 5. Picture taken during a settling column test. The left image shows the full column for a test with a high initial concentration. Note how the concentration varied between the top and the bottom of the settling column as shown in the right-most panes.

Fig. 6. Harbor bed sediment settling velocities.

Fig. 7. Flow discharge and suspended sediment concentrations in the Mississippi River at St. Louis, MO for the period Oct. 01, 1980 to Sep. 30, 2011.

Fig. 8. Suspended sediment concentration rating curve for the Mississippi River at St. Louis, MO. The dashed lines indicate envelopes for values equal to $0.2,0.5,2.0$, and 5.0 times the concentration values estimated with the power relation fit to the data shown in the lower right of the figure.

Fig. 9. Grain size distributions for the material in suspension in the Mississippi River at St. Louis, MO. The solid gray lines correspond to the 108 available measurements; the solid black 
line corresponds to the median grain size distribution and the dashed lines represent the $75^{\text {th }}$ and $25^{\text {th }}$ percentiles. The bulk $D_{50}$ for the material is $0.008 \mathrm{~mm}$.

Fig. 10. Grain size distributions for the bed material in the Mississippi River at St. Louis, MO. The solid gray lines correspond to the 114 available measurements; the solid black line corresponds to the median grain size distribution and the dashed lines represent the $75^{\text {th }}$ and $25^{\text {th }}$ percentiles. The bulk $D_{50}$ for the material is $0.44 \mathrm{~mm}$.

Fig. 11. Mean annual hydrograph and suspended sediment concentrations for Mississippi River at St. Louis, MO. The dashed black line indicates the mean annual concentration values when including the values observed in the period Feb. $22^{\text {nd }}-26^{\text {th }}, 1985$.

Fig. 12. Mean annual flow $(Q)$ duration curve and mean annual suspended sediment concentration (C) duration curve for the Mississippi River at St. Louis, MO.

Fig. 13. Effective discharge analysis plots and results. The left panel shows the flow frequency curve; the middle panel shows the sediment rating curve; and the right panel shows the weighted contributions and effective discharge.

Fig. 14. Comparison of Harbor and Upper Mississippi River grain size distributions.

Fig. 15. Flow and suspended sediment concentration conditions in the Upper Mississippi River at St. Louis, MO for hydrologic years 2008-2010, as well as harbor siltation volumes and rates. 
Table 1. Siltation volumes in the harbor and corresponding mean siltation rates for the period between February 2008 and June 2010.

\begin{tabular}{ccccccc}
\hline Date & $\begin{array}{c}\text { Excess } \\
\text { Volume } \\
\text { of Sediment } \\
{\left[\mathrm{m}^{3}\right]}\end{array}$ & $\begin{array}{c}\text { Volume } \\
\text { Increase } \\
{\left[\mathrm{m}^{3}\right]}\end{array}$ & $\begin{array}{c}\text { Time } \\
{[\text { days }]}\end{array}$ & $\begin{array}{c}\text { Mean Daily } \\
\text { Siltation } \\
\text { Rate } \\
{\left[\mathrm{m}^{3} / \text { day }\right]}\end{array}$ & $\begin{array}{c}\text { Equivalent } \\
\text { Deposit } \\
\text { Thickness }^{2} \\
{[\mathrm{~m}]}\end{array}$ & $\begin{array}{c}\text { Avg. Daily } \\
\text { Siltation } \\
\text { Depth }^{3} \\
{\left[\mathrm{~cm}^{2} \mathrm{~m}^{2} / \mathrm{day}\right]}\end{array}$ \\
\hline FEB 28 2008 & 166,444 & - & - & - & - & - \\
AUG 13 2008 & 363,540 & 197,095 & 167 & 1,180 & 3.6 & 1.2 \\
OCT 04 2008 & 337,617 & 0 & 52 & 0 & 3.4 & 0.0 \\
JAN 26 2009 & 52,699 & 0 & 114 & 0 & 0.5 & 0.0 \\
MAR 10 2009 & 57,271 & 4,572 & 43 & 106 & 0.6 & 0.1 \\
JUN 04 2009 & 159,829 & 102,557 & 86 & 1,193 & 1.6 & 1.2 \\
JUL 28 2009 & 211,052 & 51,224 & 54 & 949 & 2.1 & 1.0 \\
DIC 16 2009 & 199,168 & 0 & 141 & 0 & 2.0 & 0.0 \\
FEB 10 2010 & 207,347 & 8,178 & 56 & 146 & 2.1 & 0.2 \\
JUN 02 2010 & 299,332 & 91,986 & 112 & 821 & 3.0 & 0.8 \\
\hline
\end{tabular}

\footnotetext{
${ }^{1}$ Mean siltation rate determined by dividing the volume increase between consecutive surveys by the number of days between them.

2 Equivalent deposit thickness computed by dividing the excess volume of sediment by the total harbor area $\left(500 \mathrm{~m}\right.$ by $\left.200 \mathrm{~m}-10,000 \mathrm{~m}^{2}\right)$ assuming it is uniformly distributed.

${ }^{3}$ Average daily siltation depth is computed by dividing the mean daily siltation rate by the total harbor area.
} 
Table 2. Harbor bed sediment sample dates and volumes.

\begin{tabular}{cccc}
\hline Date & \multicolumn{2}{c}{ Dec. 2010 } & Dec. 2011 \\
Sample(s) & Drum & $1-9$ & A-C \\
Volume & $189 \mathrm{~L}$ & $1.9 \mathrm{~L}$ & $3.8 \mathrm{~L}$ \\
\hline
\end{tabular}

564

565 
Table 3. Settling process zones

\begin{tabular}{cccc}
\hline Zone 1 & Zone 2 & Zone 3 & Zone 4 \\
Free settling & Flocculation settling & Hindered Settling & Consolidation \\
$\mathrm{C}<\mathrm{C}_{1}$ & $\mathrm{C}_{1}<\mathrm{C}<\mathrm{C}_{2}$ & $\mathrm{C}_{2}<\mathrm{C}<\mathrm{C}_{3}$ & $\mathrm{C}_{3}<\mathrm{C}$ \\
$\mathrm{w}_{\mathrm{s}}=\mathrm{w}_{\mathrm{sf}}$ & $\mathrm{w}_{\mathrm{s}}=\mathrm{w}_{\mathrm{s}}(\mathrm{C})$ & $\mathrm{w}_{\mathrm{s}}=\mathrm{w}_{\mathrm{s}}(\mathrm{C})$ & $\mathrm{w}_{\mathrm{s}} \rightarrow 0$ \\
\hline
\end{tabular}

568 
569 Table 4. Coefficients used in Eq. 1 to fit the measured harbor sediment settling velocities.

\begin{tabular}{ccccccc}
\hline Coefficient & $\mathrm{a}_{\mathrm{w}}$ & $\mathrm{n}_{\mathrm{w}}$ & $\mathrm{b}_{\mathrm{w}}$ & $\mathrm{m}_{\mathrm{w}}$ & $\mathrm{C}_{2}[\mathrm{~g} / \mathrm{L}]$ & $\mathrm{w}_{\mathrm{sm}}[\mathrm{m} / \mathrm{s}]$ \\
Value & 0.1 & 2.1 & 10 & 2.08 & 10.1 & $2.1 \mathrm{e}-4$ \\
\hline
\end{tabular}

570

571

572 
573 Table 5. Summary of available data from USGS gaging stations at St. Louis, MO and Chester, IL that were used in the study.

\begin{tabular}{ccc}
\hline \multicolumn{3}{c}{ USGS 07010000 Mississippi River at St. Louis, MO } \\
\hline Daily Data & Begin Date & End Date \\
Discharge & $01 / 01 / 1861$ & $09 / 30 / 2011$ \\
Suspended sediment & $10 / 01 / 1980$ & $09 / 30 / 2011$ \\
Field/lab water-quality samples & $01 / 31 / 1953$ & $09 / 30 / 2011$ \\
\hline \multicolumn{2}{c}{ USGS 07020500 Mississippi River at Chester, IL } \\
\hline Daily Data & Begin Date & End Date \\
Discharge & $07 / 01 / 1942$ & $09 / 30 / 2011$ \\
Suspended sediment concentration & $10 / 01 / 1982$ & $09 / 30 / 2011$ \\
Field/lab water-quality samples & $10 / 14 / 1970$ & $09 / 30 / 2011$ \\
\hline
\end{tabular}

575 

correspond to hydrologic years.

\begin{tabular}{cccccc}
\hline Period & {$[$ years } & $1861-2011^{\mathrm{a}}$ & $1941-2011^{\mathrm{b}}$ & $1981-2011^{\mathrm{c}}$ & $2007-2011^{\mathrm{d}}$ \\
Mean Flow & {$\left[\mathrm{m}^{3} / \mathrm{s}\right]$} & 5,265 & 5,665 & 6,175 & 8,210 \\
\hline
\end{tabular}

a Complete period of record for Mississippi River discharge at St. Louis, MO.

${ }^{b}$ Period of record matching the discharge data available at Chester, IL.

${ }^{c}$ Period of record matching the suspended sediment concentration measurements at St.

Louis, MO

${ }^{d}$ Period of record beginning in the year when the harbor started operating (2007). 
Table 7. Suspended sediment concentration values measured in 1985 and associated flow discharges.

\begin{tabular}{lcc}
\hline Date & Flow Discharge $Q\left[\mathrm{~m}^{3} / \mathrm{s}\right]$ & Suspended Sediment Concentration C [g/L] \\
\hline Feb. 22 1985 & 6,343 & 2.75 \\
Feb. 23 1985 & 11,836 & 5.74 \\
Feb. 24 1985 & 15,348 & 6.72 \\
Feb. 25 1985 & 17,302 & 5.69 \\
Feb. 26 1985 & 18,632 & 3.09 \\
\hline
\end{tabular}

a The $99^{\text {th }}$ percentile for concentrations measured in the period Oct. $1^{\text {st }} 1980$ to Sep. $30^{\text {th }} 2011$ is $1.78 \mathrm{~g} / \mathrm{L}$. Within that time period, only $3(12,30)$ values exceeded $4 \mathrm{~g} / \mathrm{L}(3 \mathrm{~g} / \mathrm{L}, 2.5 \mathrm{~g} / \mathrm{L})$ corresponding to $0.03 \%(0.11 \%, 0.27 \%)$ of the data. 
Table 8. Median $D_{50}$ values for Harbor and Upper Mississippi River sediment grain size distributions.

\begin{tabular}{lccc}
\hline \multirow{2}{*}{ Sediment source } & \multicolumn{2}{c}{ Median $\mathrm{D}_{50}[\mathrm{~mm}]$} \\
& & Dispersed & Non-dispersed \\
\hline \multirow{3}{*}{ Harbor } & Drum & 0.008 & 0.040 \\
& S1-9 & 0.017 & 0.022 \\
& A-C & 0.015 & 0.050 \\
\multirow{2}{*}{ River } & Suspended & \multicolumn{2}{c}{0.008} \\
& Bed & \multicolumn{2}{c}{0.440} \\
\hline
\end{tabular}

587 
Table 9. Upper Mississippi River at St. Louis, MO characteristic discharges, exceedance and associated suspended sediment concentrations for hydrologic years 1981-2011.

\begin{tabular}{cccc}
\hline $\begin{array}{c}\text { Discharge } \\
\text { Type }\end{array}$ & $\begin{array}{c}\text { Discharge Value } \\
\mathrm{Q}\left[\mathrm{m}^{3} / \mathrm{s}\right]\end{array}$ & $\begin{array}{c}\text { Exceedance } \\
\text { [days - \%] }\end{array}$ & $\begin{array}{c}\text { Associated Suspended Sediment } \\
\text { Concentration C [g/L] }\end{array}$ \\
\hline Mean & 6,170 & $162-44 \%$ & 0.264 \\
Dominant & 7,608 & $120-33 \%$ & 0.337 \\
Effective & 9,582 & $36-10 \%$ & 0.441 \\
\hline
\end{tabular}




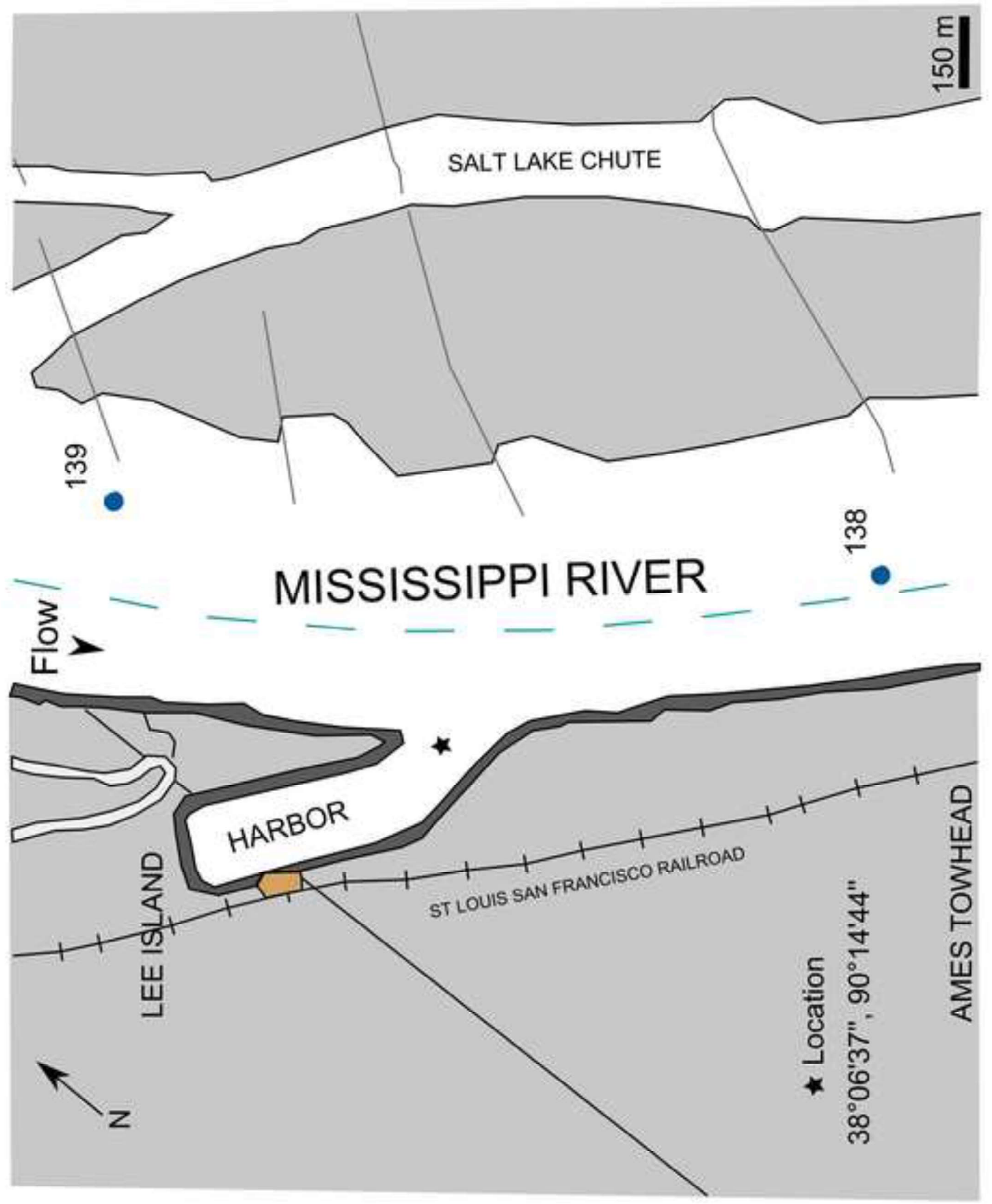




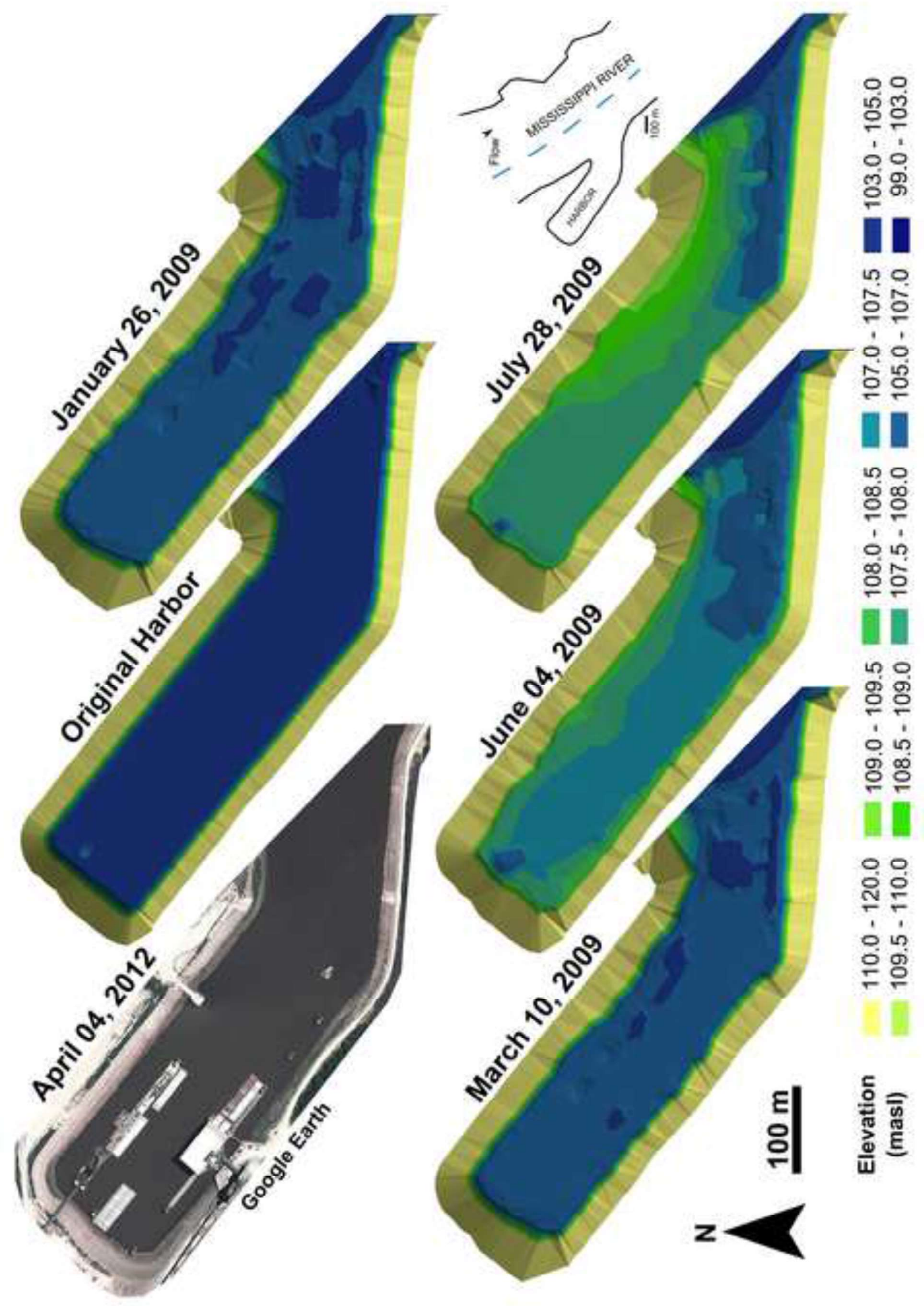

구
음
은 


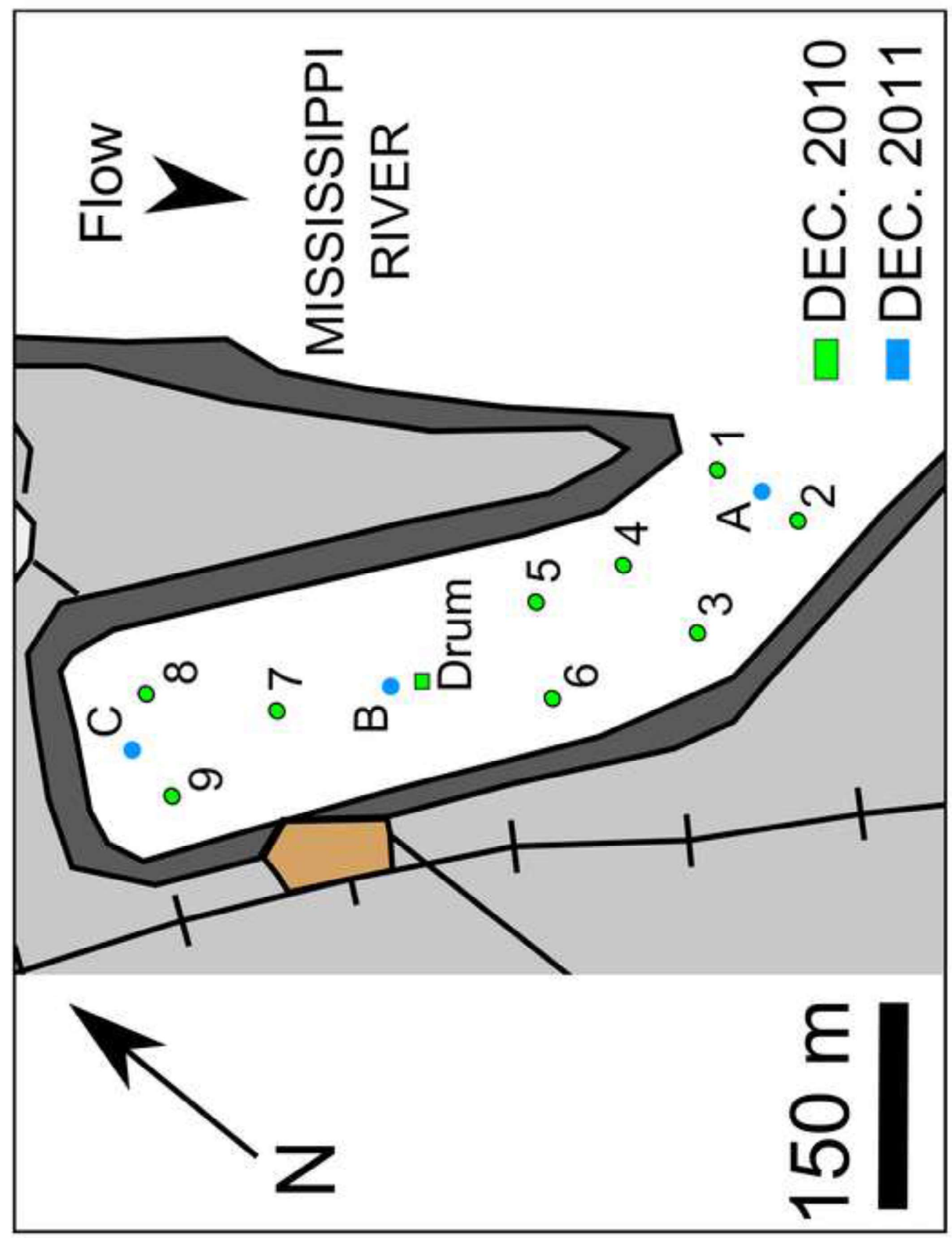




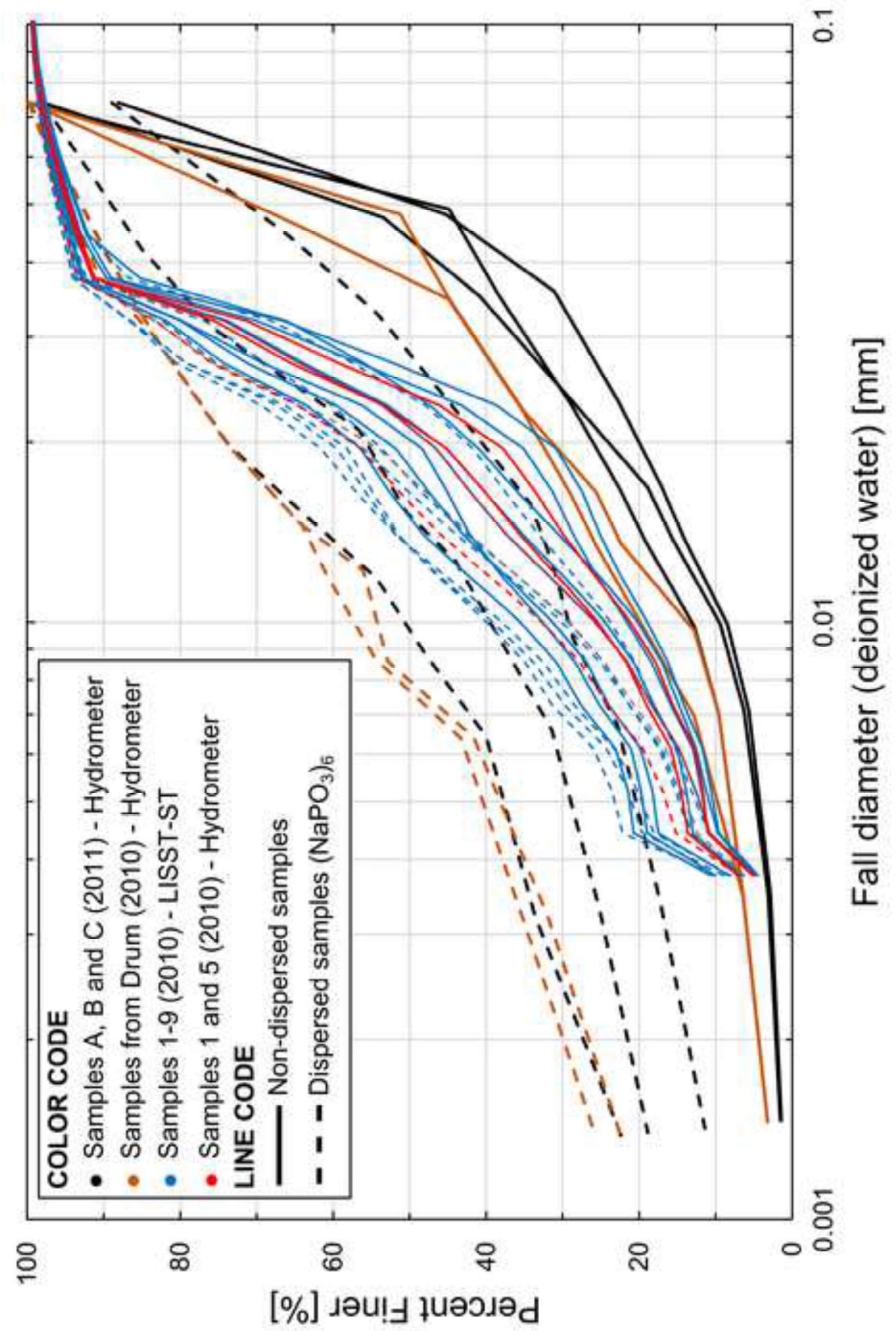




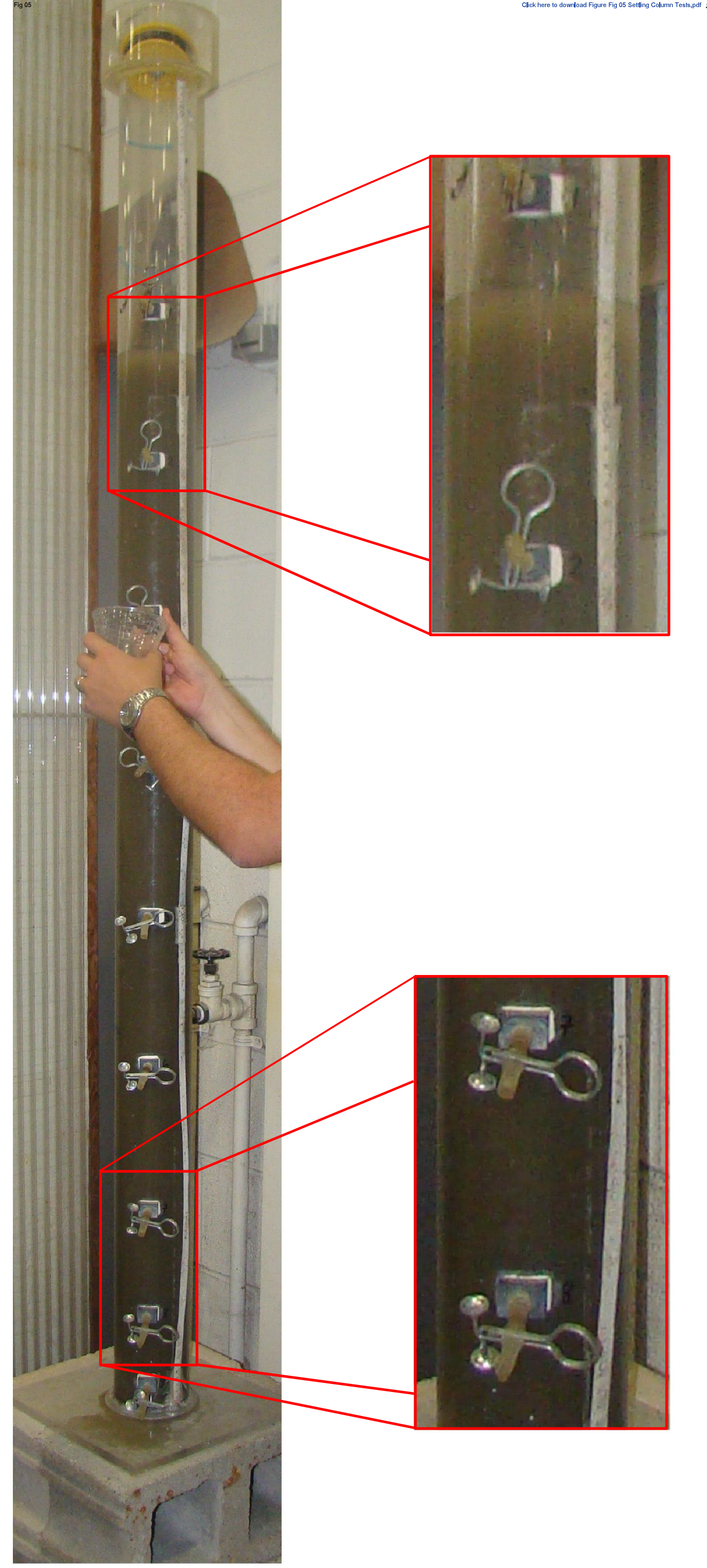




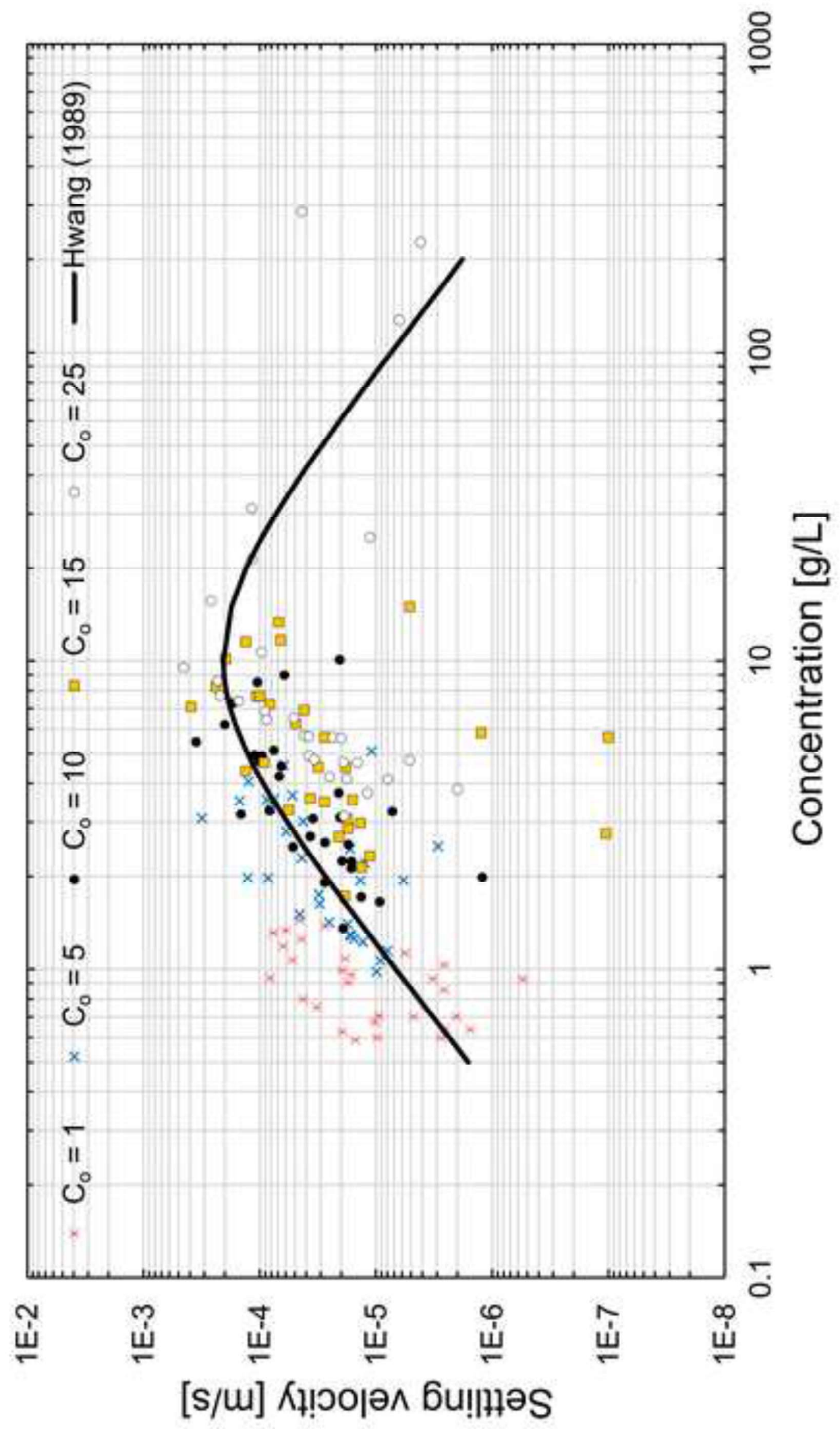

0
0
은 


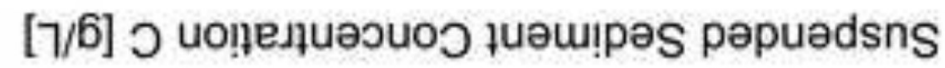

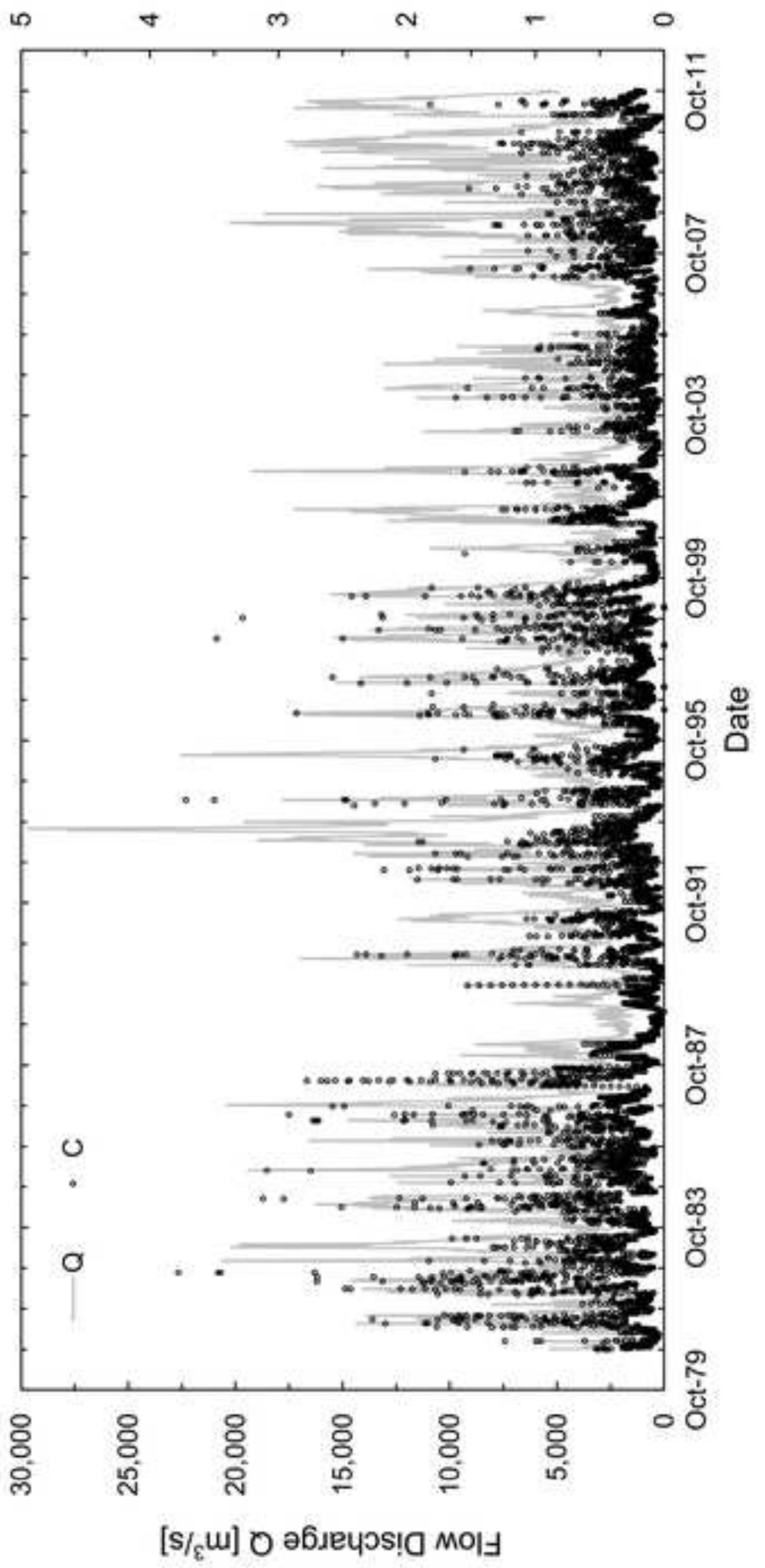




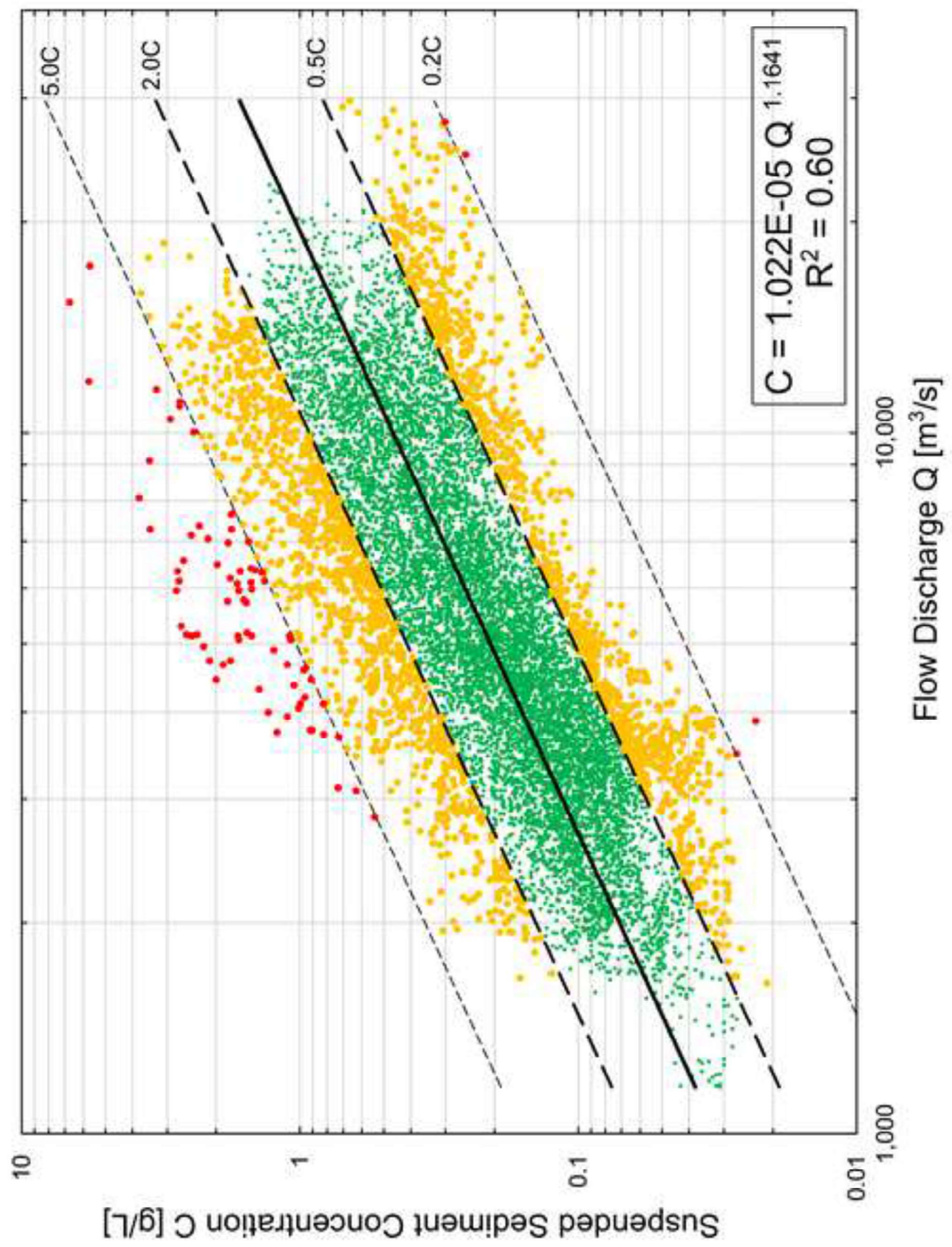

$\infty$
$\stackrel{\circ}{\circ}$
운 


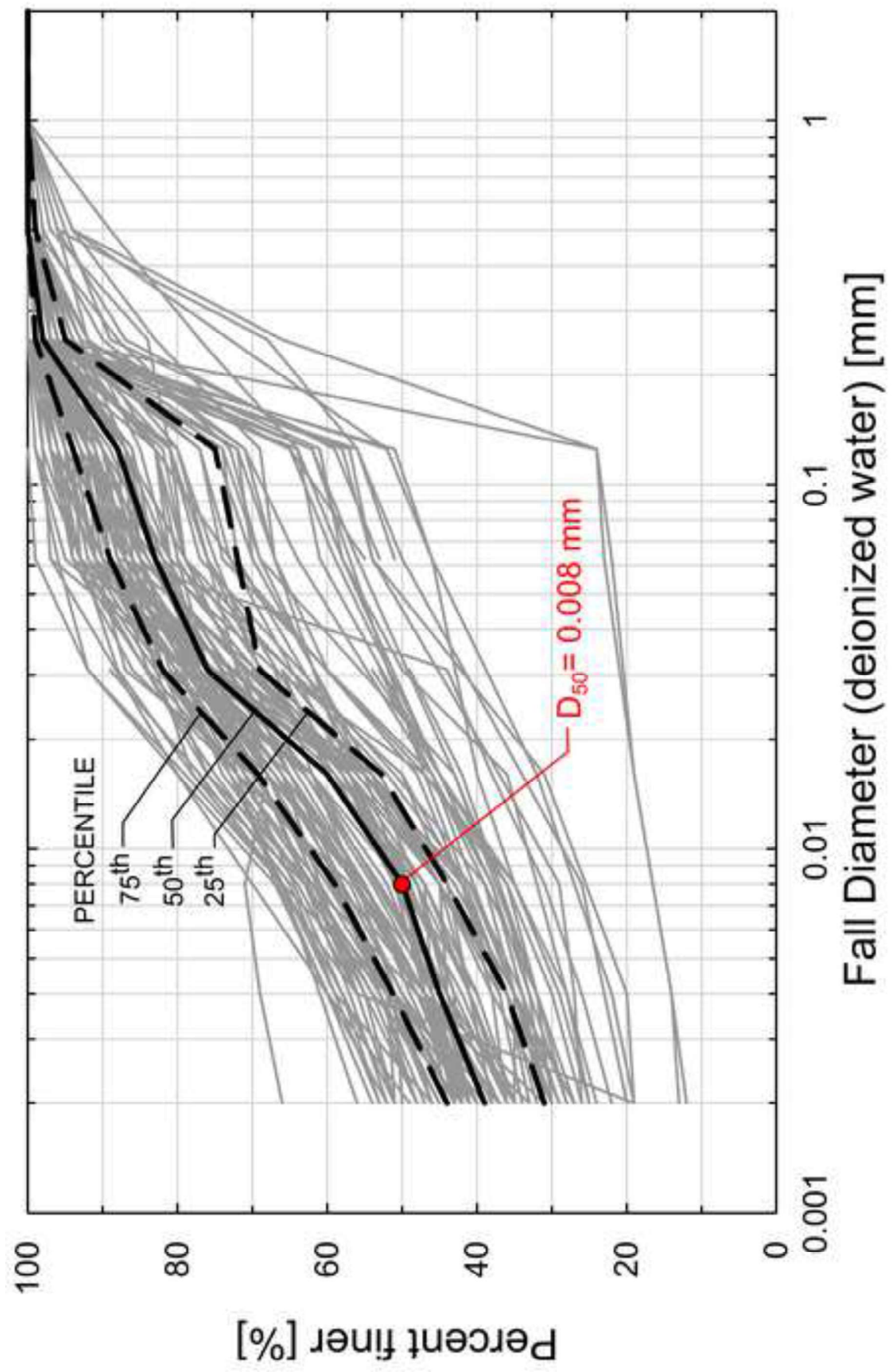

옹
은 


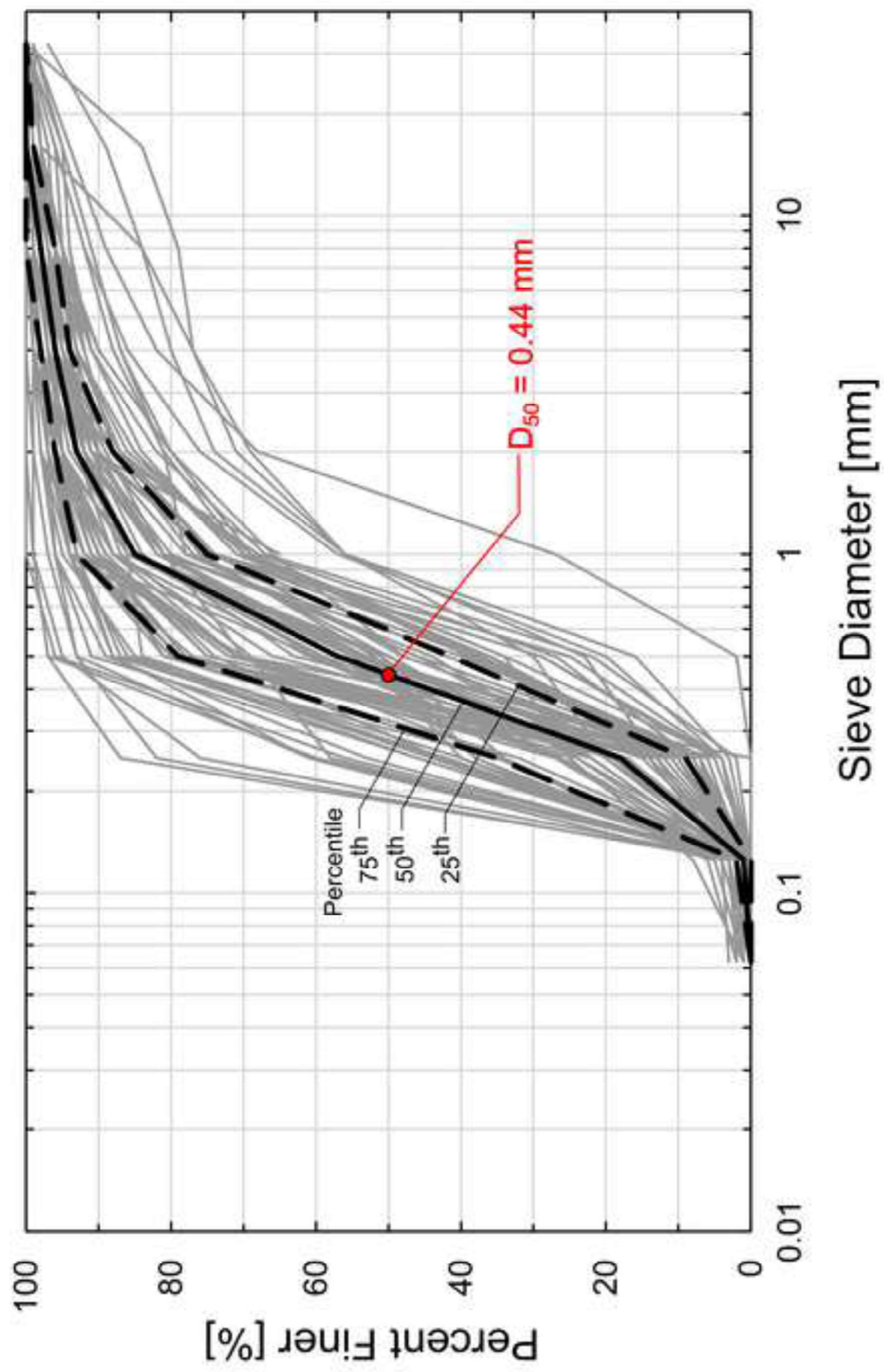

$\frac{0}{ㅇ ㅡ ㄴ ~}$ 


\section{[7/6] ว uo!̣enuəouoว ұuәu!pəs pəpuədsns}

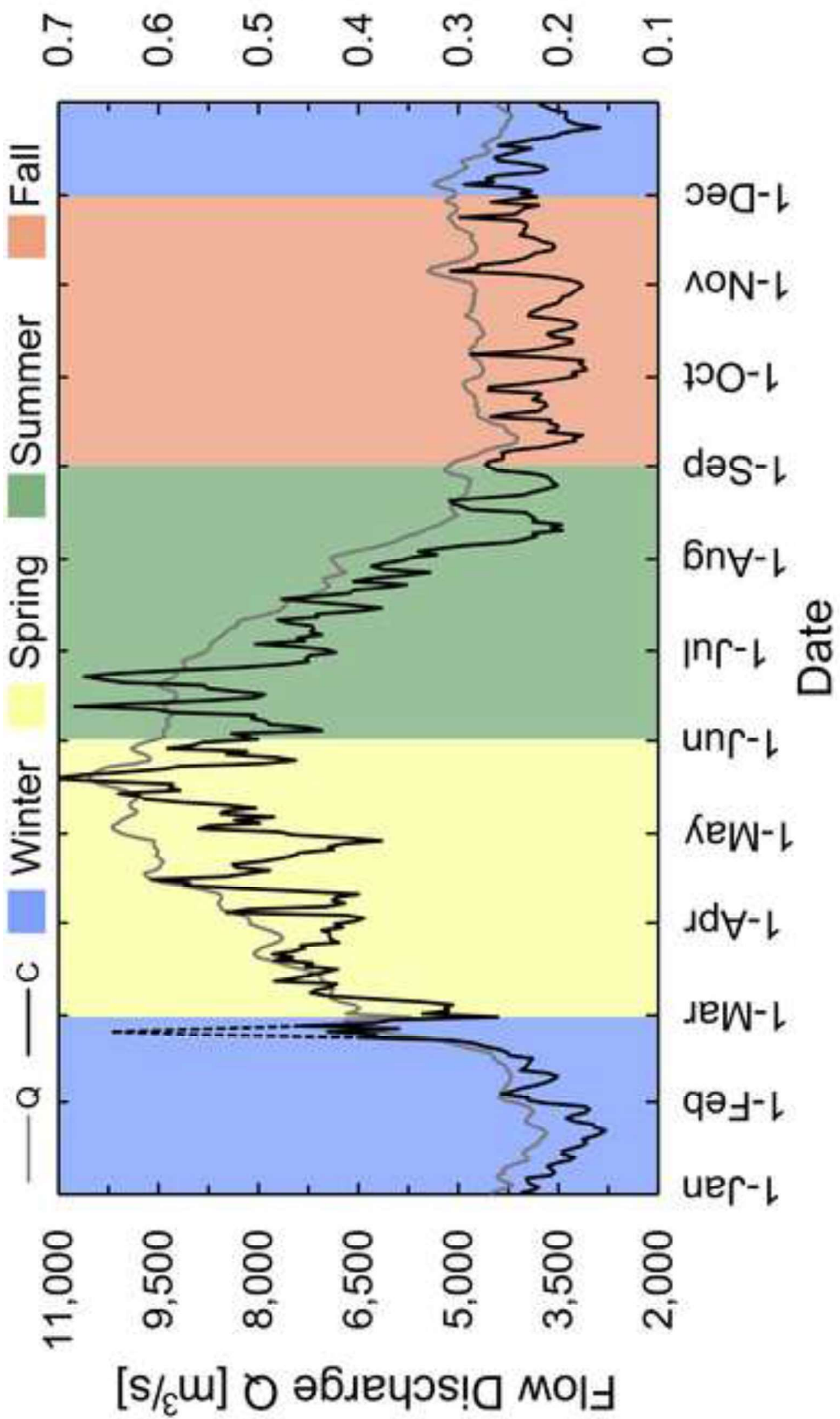




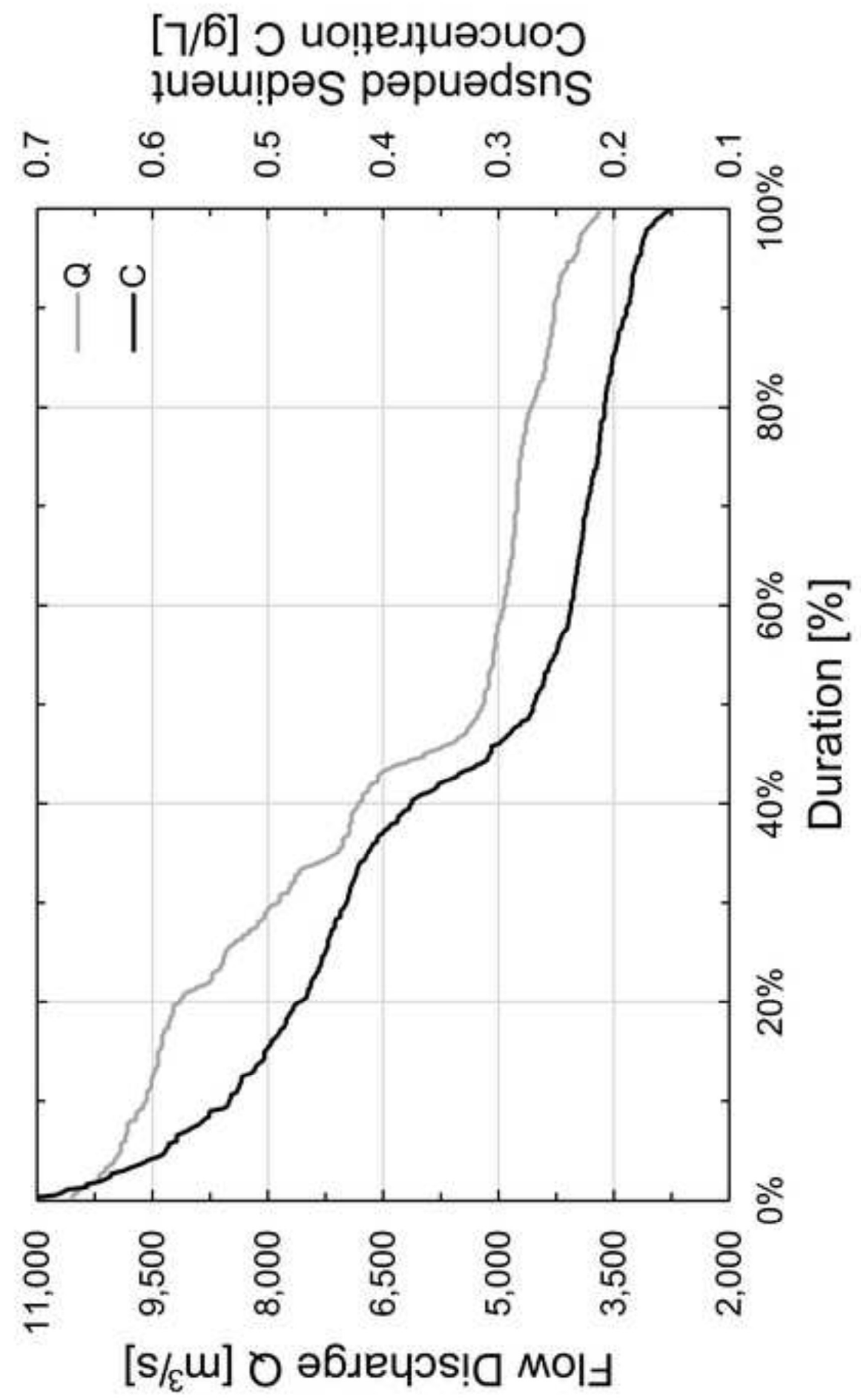



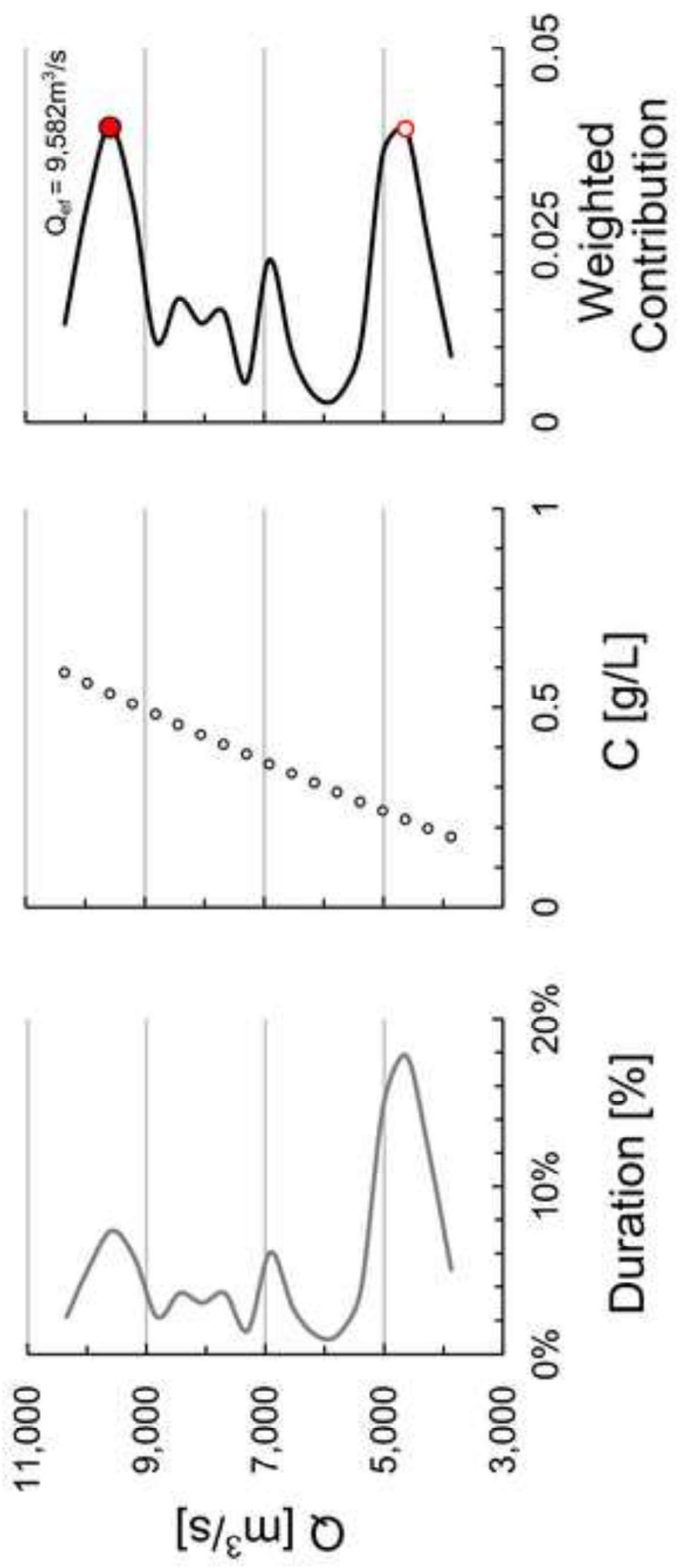


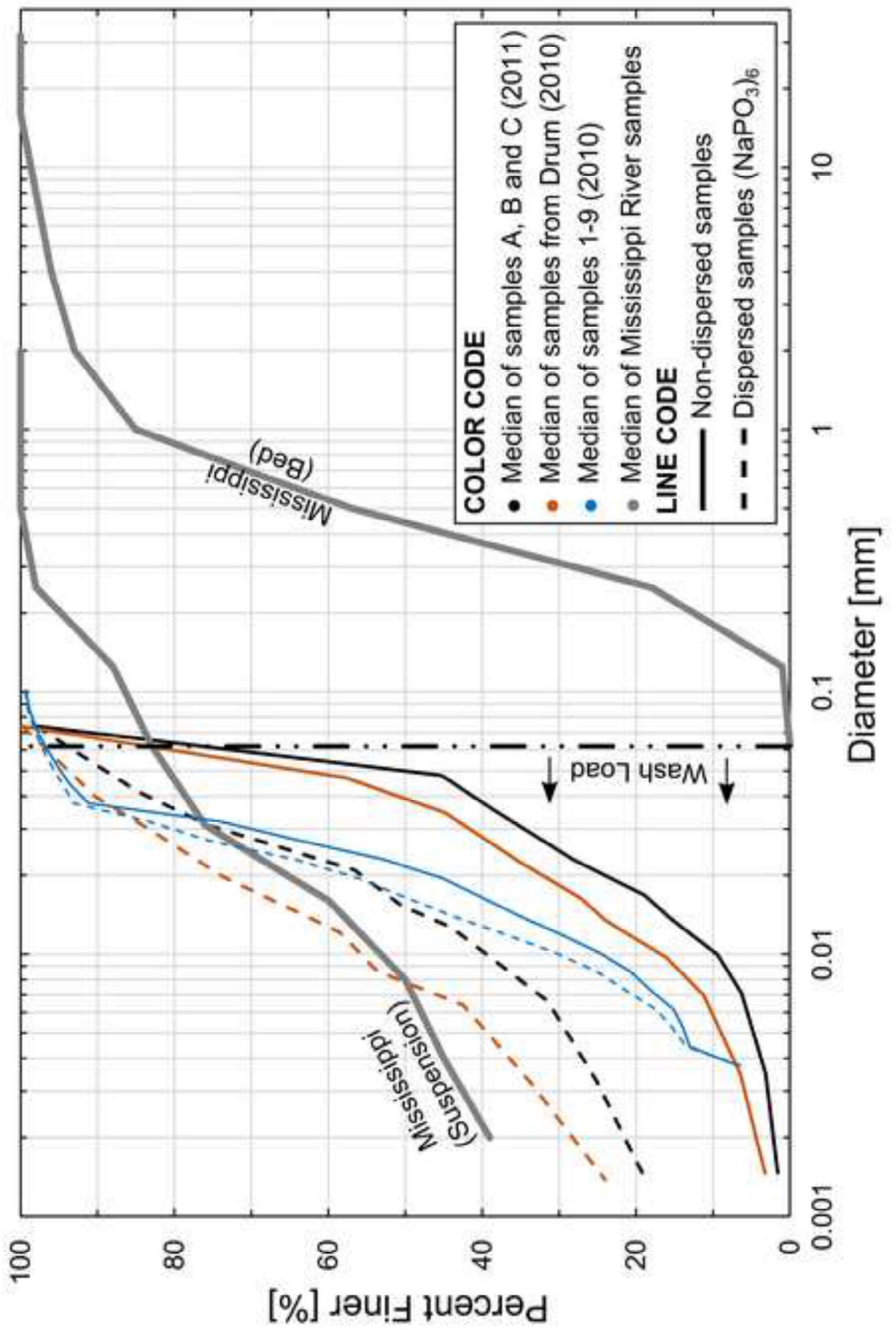




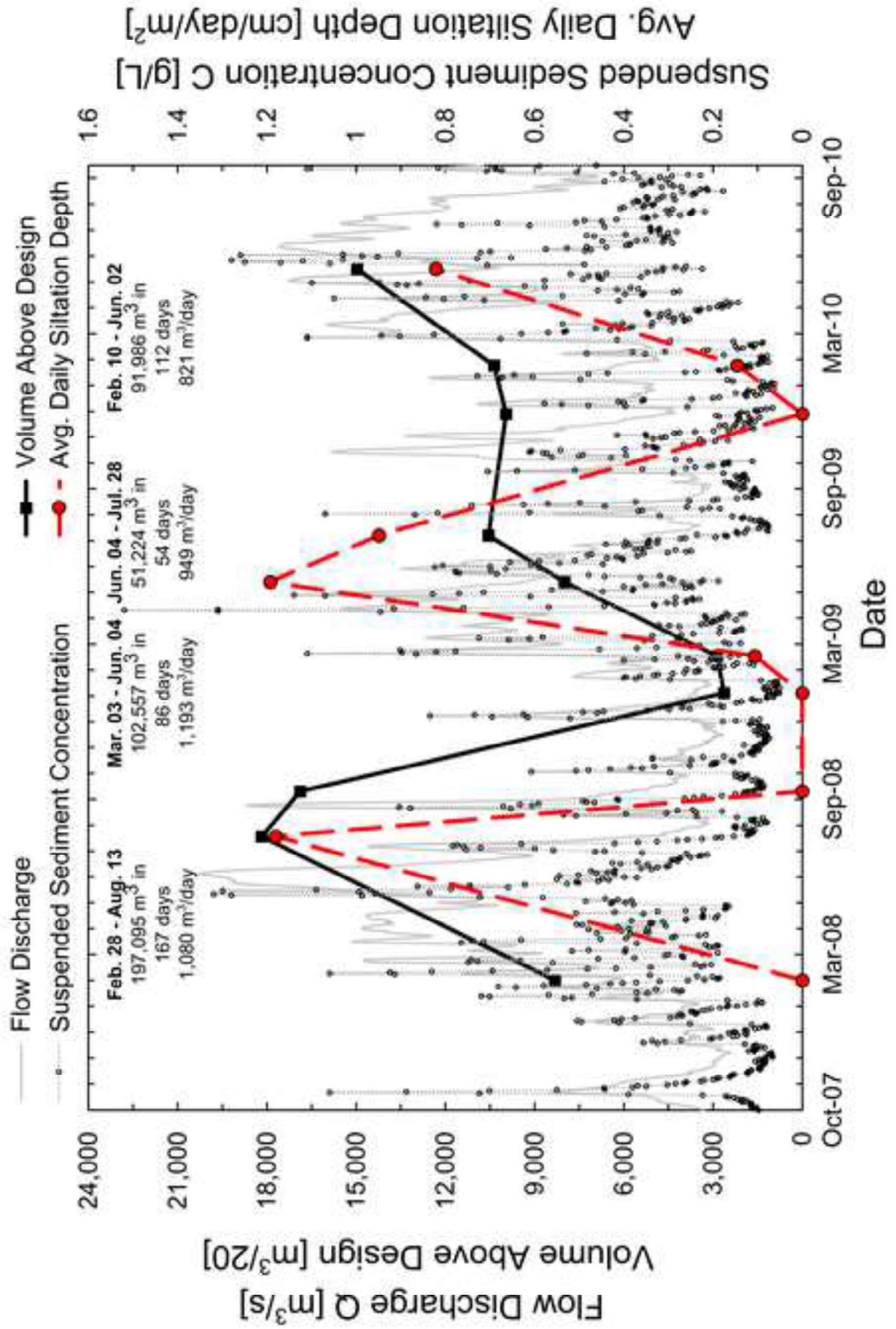

